\title{
Quantitative Determination of the Chromophore Alignment Induced by Electrode Contact Poling in Self-Assembled NLO Materials
}

\author{
Tae-Dong Kim, ${ }^{*}$ Jingdong Luo, ${ }^{\dagger}$ and Alex K-Y. Jen ${ }^{\dagger{ }^{*}}$

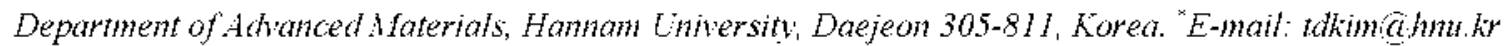 \\ -Deparment of Material Sciences and Engineering, and Institute of $t$ dvanced Materials and Technologv, \\ Intwersity of Washington, Seattle, WA 98195-2120, LSA. *E-mail: ajenau washington edu \\ Received November 11, 2008, Accepted March 3. 2009
}

\begin{abstract}
The electrode contact poling is one of the efficient tools to induce a stable polar order of nonlinear optical (NLO) chromophores in the solid film. Self-assembled NLO chromophores with high electro-optic (E-O) activities were utilized for quantitative determination of the chromophore order induced under contact poling by spectroscopic changes. We found that $\mathrm{NLO}$ chromophores rarely decompose under the high electric field during contact poling. The absorption spectra were de-convoluted into a sun of Gaussian components to separate energy transitions for a binary composite system which contains a secondary guest chromophore AJCl46 in the self-assembled chromophore HDFD. Poling efficiency was significantly improved in the binary system compared to the individual components.
\end{abstract}

Key Wonds: Nonlinear optics. Chromophore. Self-assembly. Order parameter. Contact poling

\section{Introduction}

Organic second-order nonlinear optical (NLO) materials have been numerously investigated for their potential applications from electro-optic (E-O) modulators to $\mathrm{THz}$ generation applications. ${ }^{1.2}$ Recent advances in the use of highly efficient organic NLO materials with nino-scale architecture control have lead to significant breakthrough in the E-O devices exceeding those of inorganic materials by a factor of $5 \sim 6 .{ }^{3.4}$

It is well known that second-order NLO properties originate from noncentrosy'mmetric alignment of dipolar NLO chromophores in a polymer matrix. A commonly used method to align the chromophore is through the application of an external electric field at elevated temperatures either by contact poling or corona poling methods. "For the contact poling. a direct contact (DC) voltage applied between bottom and top electrodes produces a controlled electric field across the NLO poly mer film. Chromophores will be aligned perpendicular to the surface plane of the sample. A single defect created during the film processing may introduce a short circuit. destroying the devices. However it is a preferred method because E-O coefficient $\left(r_{33}\right)$ of the sample can be directly measured by simple reflection technique after the poling. In the corona poling a high voltage is applied to a thin wire or needle which is placed several millimeters above the film. Although poling efficiency is lower than that of the contact method, it has been used for stidy ing the orientational order by the spectroscopic changes or Maker fringe technique.

We have developed novel NLO molecular glasses and their composites based on a reversible self-assembly of dendronized chromophores using the arene-perfluoroarene interactions $\left(\mathrm{Ar}-\mathrm{Ar}^{\mathrm{F}}\right)$ that can be reorganized into a stable acentric polar structure. One such composite glass showed an extremely large $r_{33}$ of $327 \mathrm{pm} / \mathrm{V}$ at the wavelength of $1.31 \mu \mathrm{m}$ after the contact poling. ${ }^{8}$ Although the results are very encouraging for the organic materials. it is also important to evaluate orientational order to determine the efficiency and persistence of chromophore alignment after the poling.

We report. here. quantitative determination of the polar ordering for self-assembled chromophores induced under the contact poling by spectroscopic changes. In addition, a binary composite system which contains a secondary guest cluromophore in self-assembled chromophores has been utilized to assess high $\mathrm{E}-\mathrm{O}$ activities. These results will provide insight into the systematic optimization of E-O activities and guide the alignment efficiency of the poled organic E-O materials.

\section{Experimental Section}

HDFD and AJC146 chromophores were designed and sy nthesized in our laboratories. Detailed sy nthetic procedures are described in the literature ${ }^{8}$ All reactions were carried out under inert nitrogen atmosphere. Reliable and pinhole-free films can be prepared by spin-coating onto indium tin oxide (ITO) glass substrate from the 1.1.2-trichloroethane solution after the filtration through a $0.2 \mu \mathrm{m}$ poly (tetrafluoroetlylene) (PTFE) filter. Carefully controlled spin-coating speed and concentration of the solution were used for the suitable thickness of the film ranged from $0.3 \mu \mathrm{m}$ to $2.0 \mu \mathrm{m}$. The films were then dried under high vacuum at $40{ }^{\circ} \mathrm{C}$ for $10 \mathrm{hrs}$ to remove any residual solvent. UV/vis spectra were obtained on a Perkin-Elmer Lambda-9 spectrophotometer. Atomic Force Microscopy (AFM) was performed in the tapping mode using a Nanoscope III AFM (Digital Instruments) operating in ambient conditions at a scan rate of $0.5-1.0 \mathrm{~Hz}$. Roughness measurements and cross-sectional analysis were performed using algorithm contained in the AFM software. The $r_{33}$ values were measured using the simple reflection technique at the wavelength of $1.31 \mu \mathrm{m}$. $^{g}$ 


\section{Results and Discussion}

Molecular structures of the chromophores studied are shown in Figure 1. For the chromophore, HDFD, phenyl and pentafluorophenyl rings have been incorporated as peripheral groups to form supramolecular self-assembled NLO chromophores by $\mathrm{Ar}-\mathrm{Ar}$. The core of the molecule is a $\mathrm{CF}_{3}-\mathrm{TCF}$ based (namely 2-dicyanomethylene-3-cyano-4,5dimethy $1-5$ trifluoromethyl-2,5-dilydrofuran) conjugative structure, which is the skeleton of a well-established chromophore for guesthost $\mathrm{E}-\mathrm{O}$ polymers. ${ }^{\text {]D }}$

AJC146 is a newly developed and more efficient polyenic chromophore as a secondary guest ${ }^{11}$ and can be doped in HDFD. The self-assembled chromophore and composite system were poled and characterized using device fabrication procedures as described in Figure 2. The conductive ITO and sputtered gold serve as electrodes used for poling and E-O modulation. For the poling process, DC voltage was turned on at the very beginning stage and slowly increased temperature with $5{ }^{\circ} \mathrm{C} / \mathrm{min}$ was used to avoid possible film damage. We found that optimal poling temperature was around $70^{\circ} \mathrm{C}$ corresponding to the glass transition temperature of HDFD. The films were then cooled to room temperature while the electric field was maintained. After measurement of $r_{33}$ at $1.31 \mu \mathrm{m}$ by simple reflection method for the poled films, the gold electrode was removed by KI etchant solution. which does not attack NLO materials. It is noted that films thermally treated without any electric field have been also used to compare surface morphology and absorption spectra.

The chromophore HDFD gave $108 \mathrm{pm} / \mathrm{V}$ of the $r_{3 z}$ value applied by $100 \mathrm{~V} / \mu \mathrm{m}$ of poling field strength. This result interpreted high chromophore ordering with improved dielectric strength induced from the formation of supramolecular self-assembly through the Ar-Ar ${ }^{\mathrm{F}}$ interactions. ${ }^{12}$ It is well known that well-ordered supramolecular materials through intermolecular forces can provide novel electronic and photonic properties. ${ }^{13}$ These poled thin films retained over $90 \%$ of their original $r_{33}$ values at $50^{\circ} \mathrm{C}$ for a month. Futher attempts to raise chromophore loading density and the $r_{33}$ of these materials were conducted by adding more efficient AJC146 guest chromophore to HDFD host chromophore. The resulting binary systems exhibited extraordinary high $r_{33}$ values. 275 $\mathrm{pm} / \mathrm{V}$ for the composite of HDFD $\mathbf{A J C} 1+6=3: 1$ (wt.\%) and $327 \mathrm{pm} / \mathrm{V}$ for the composite of HDFD : $\mathbf{A J C 1}+6=1: 1$ (wt $\%$ ).

One of the popular and simple approaches to quantitatively determine the degree of chromophore orientation is to measure the order parameter by absorption change. Most work has been performed from the corona poling. Knoesen and coworkers have described the axial orientation of the chromophores by the order parameter $\Phi=1-\left(\mathrm{A}_{\mathrm{A}}\right)$. where $\mathrm{A}_{i}$ and $\mathrm{A}$ are respectively the absorbance maxima for the unpoled and poled samples at normal incidence. ${ }^{14}$ However, effects other than chromophore orientation can cause changes in the absorption spectrum during poling. Sublimation of the cluromophore out of the polymeric host or thermal decomposition of the chromophore at the poling temperature can lead to reductions in the absorption not related to the poling order. In addition.

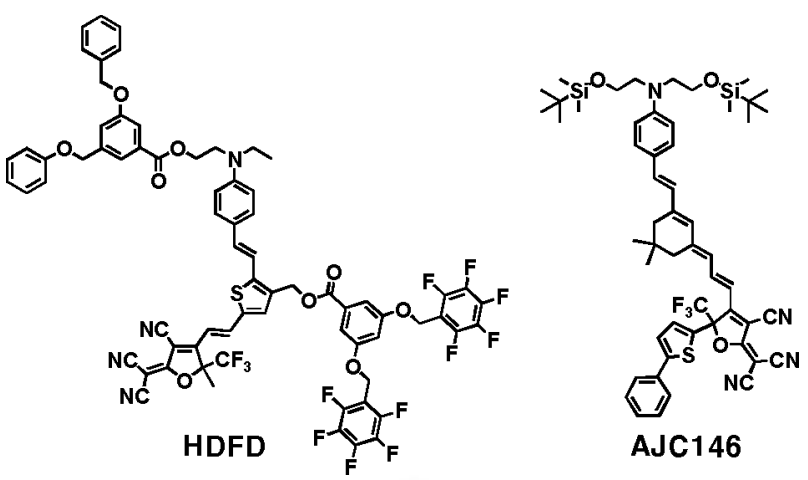

Figure 1. Molecular Structures for HDFD as a self-assembled chromophore and AJC146 as a secondary guest chromophore.

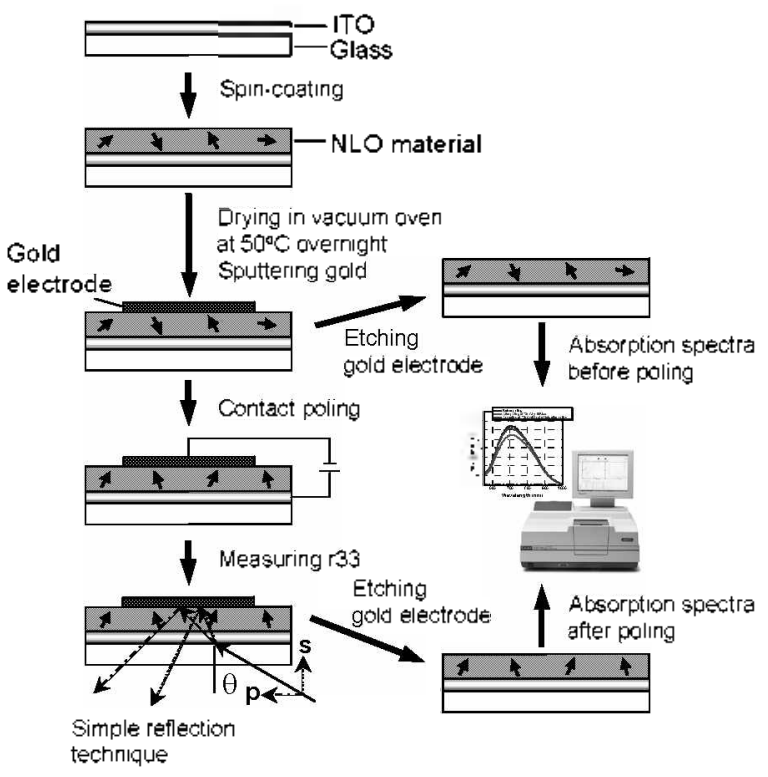

Figure 2. 'l'he schematic dagram of device fabncation procedures for the order parameter detemination of dipolar chromophores.

the electric field applied during the poling process can lead to irreversible absorption changes. Furthermore. it is rarely reported the order parameter from contact poling due to the low alignment efficiency and poor surface quality after removing sputtered gold top electrode. ${ }^{15}$ Therefore before we determine the polar order by an absorption change, it should address surface roughness change and degradation of the chromophores induced by high electric field for the contact poling.

Atonic force microscopy (AFM) was utilized to exanine the morphology of the unpoled and poled films. The surface before sputtering a gold electrode was relatively flat and defects such as pinholes or aggregation were hardly observed. The surface roughness was estimated to be less than $1 \mathrm{~nm}$ by AFM shown in Figure 3. The remarkable film quality of HDFD chromophore itself is due to an extended solid stnucture through $\mathrm{Ar}-\mathrm{Ar}^{\mathrm{F}}$ interactions. A little of unevenly distributed defects were generated from the poled film applied with 75 $\mathrm{V} / \mu \mathrm{m}$ of an electric field. The surface rougluness of most area was found to be around $\mathrm{I} \sim 2 \mathrm{~nm}$. 

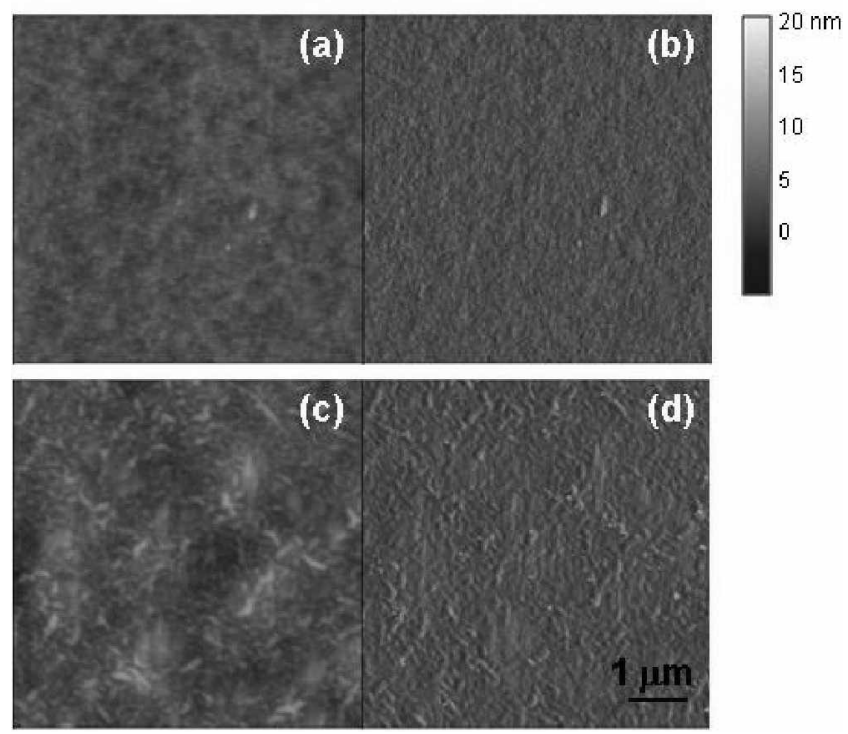

Figure 3. (a) Height and (b) phase AFM images of unpoled HDFD and (c) height and (d) phase images of poled HDFD.

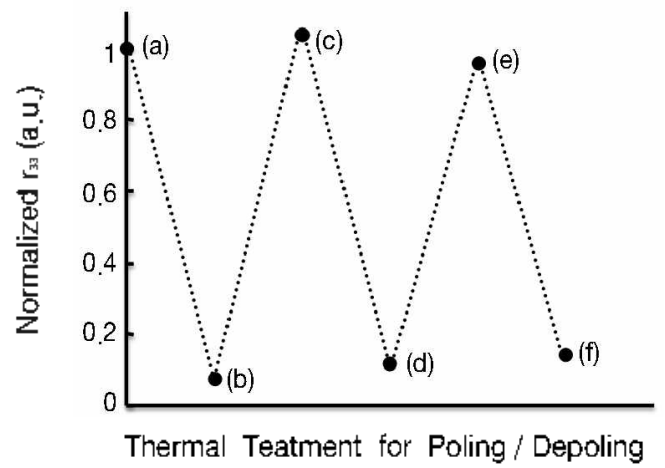

Figure 4. Thermal teversibility of E-O activities - (a) to (b), (c) to (d), (e) to (f), $70^{\circ} \mathrm{C}$ by ramping rate of $5^{\circ} \mathrm{C} / \mathrm{min}$ without a voltage; (b) to (c), (d) to (e), $70^{\circ} \mathrm{C}$ by ramping rate of $5^{\circ} \mathrm{C} / \mathrm{min}$ with $75 \mathrm{~V} / \mu \mathrm{m}$.

Although there is a little change for surface roughness of the poled film, it is still hard to indicate chromophore decomposition. which usually causes film bleaching during the poling process. We have thus performed multicycle poling and depoling treatment for the HDFD to verify thermal reversibility of E-O activities. Using $75 \mathrm{~V} / \mu \mathrm{m}$ of an electric field by $5^{\circ} \mathrm{C} / \mathrm{min}$ of ramping rate to $70^{\circ} \mathrm{C}$. we have achieved $81 \mathrm{pm} / \mathrm{V}$ of $r_{33}$. After thermal depoling treatment with 5 ${ }^{\circ} \mathrm{C} /$ min of ramping rate to $70{ }^{\circ} \mathrm{C}$ without electric fields, the $\mathrm{r}_{33}$ only retained below $10 \%$ from the original value due to chromophore alignment relaxation. When the depoled film was again applied with $75 \mathrm{~V} / \mu \mathrm{m}$ and increased to $70^{\circ} \mathrm{C}$. the $r_{33}$ showed $78 \mathrm{pm} / \mathrm{V}$, which was over $95 \%$ of the original value. The results of three cycles are shown in Figure 4 . Therefore results suggest that there is minimal sublimation and decomposition of the chromophore during the poling process.

UV/vis absorption spectra of the HDFD with and without poling are shown in Figure 5a. The main absorption peak at $70 \mathrm{Imm}$ is due to the intramolecular charge-transfer band of (a)

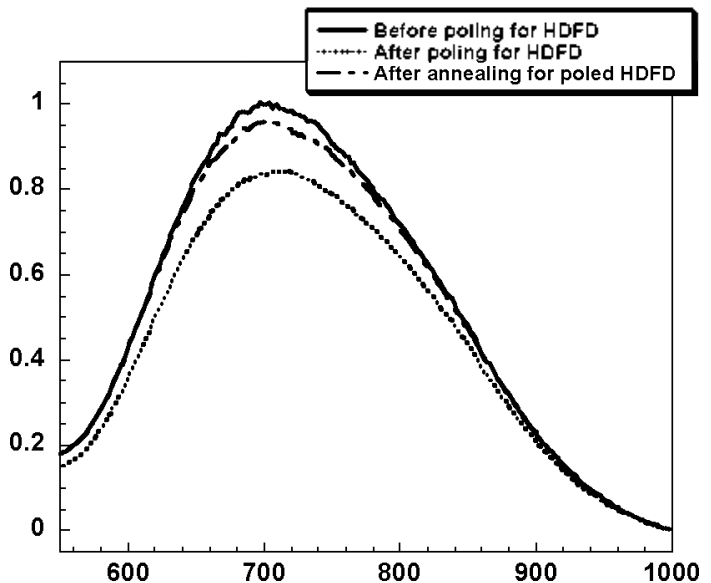

(b)

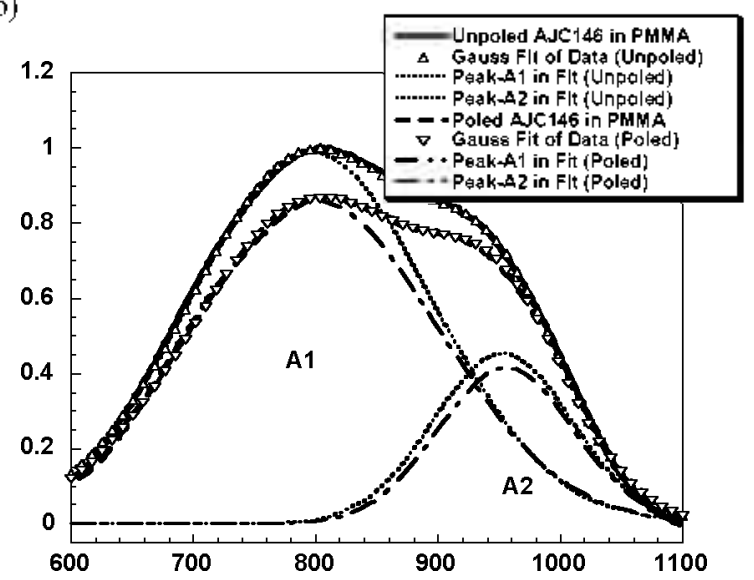

Figure 5. UV/vis absorption spectra: (a) the chromophore HDFD before poling, after poling and after thermal de-poling at $70^{\circ} \mathrm{C}$ (b) AJC146 in PMMA de-convoluted in two Gaussian components with the corresponding two-peak fittings superimposed onto the spectra.

the chromophores. The solid line was obtained with the film treated with heating to $70{ }^{\circ} \mathrm{C}$ without any electric field applied. The dotted line was obtained from the same film with $75 \mathrm{~V} / \mu \mathrm{m}$ of the electric field. The decrease of the peak absorbance is caused by the aligiment of the chromophore dipoles along the poling field direction. which is the incident light direction as well. From the absorbance change. the ordering parameter of the poled films was determined to be 0.17 with $81 \mathrm{pm} / \mathrm{V}$ of $r_{33}$. As thermal treatment proceeded again without the field for the poled film. the absorbance (dashed dotted line) was recovered over $95 \%$ due to the relaxation of the axially ordered chromophores. This is another clear indication that chromophores rarely decompose and reduced absorbance is purely from chromophore alignment by contact electric field.

A bathochromic absorption shoulder for chromophore AJC146 (25 wt.\%) in polymethylmethacrylate (PMMA) appears in the film. which suggests the favorable formation of acentric $J$-aggregates from clromophore AJC1 46 (Figure $5 b)$. The absorption spectra of the film can be de-convoluted into a simple sum of two Gaussian components ${ }^{16}$ to separate a main energy transition with an absorption shoulder centered at the wavelength of $799 \mathrm{~nm}$ and $951 \mathrm{~nm}$. We found that the 


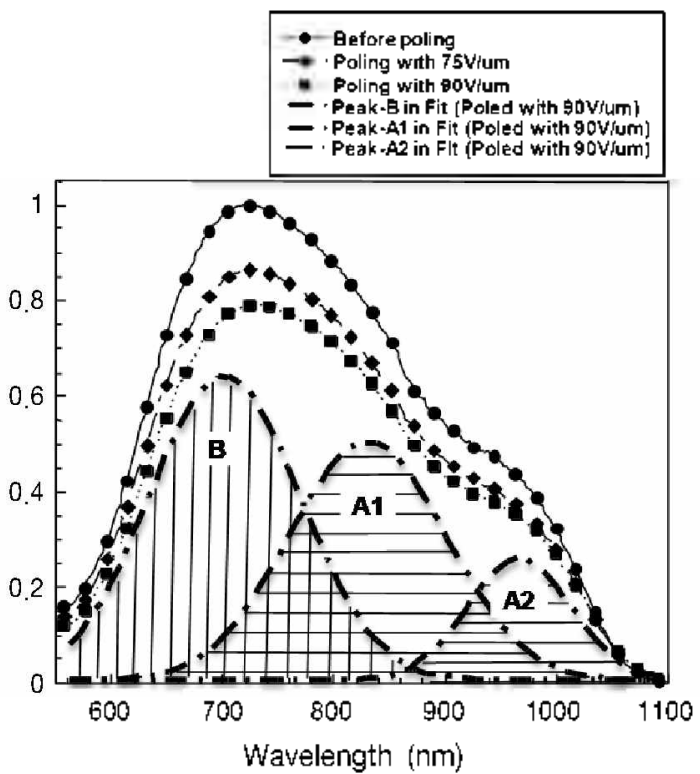

Figure 6. The absorption spectra for the composite of AJC146 in HDFD before and after poling and their Gaussian de-convolution fitting curve.

Table 1. E-O activities and optical properties for HDFD, AJC146 (25 w. \%) in PMMA, and AJC1 46 (25 wt.\%) in HDFD

\begin{tabular}{|c|c|c|c|c|c|c|}
\hline Sample & $\begin{array}{l}\text { E. Field } \\
\text { (V/um) }\end{array}$ & $\begin{array}{c}r_{33^{a}} \\
\left(\mathrm{pmw}^{2} \mathrm{~V}\right)\end{array}$ & $\Phi^{b}$ & $\begin{array}{l}\text { Unpoled } \\
\text { (Poled) } \\
\lambda_{\max (1 \mathrm{~m})}{ }^{c}\end{array}$ & $\begin{array}{l}\text { Unpoled } \\
\text { (Poled) } \\
\Gamma(11 \mathrm{~m})\end{array}$ & $\begin{array}{l}\text { Unpoled } \\
\text { (Poled) } \\
\text { Area }\end{array}$ \\
\hline HDFD & 75 & 81 & 0.17 & $\begin{array}{c}700 \\
(710)\end{array}$ & $\begin{array}{c}202 \\
(210)\end{array}$ & $\begin{array}{c}256 \\
(232)\end{array}$ \\
\hline \multirow{2}{*}{$\begin{array}{c}\text { AJC1 } 46 \\
\text { in } \\
\text { PMMA }\end{array}$} & \multirow[b]{2}{*}{100} & \multirow[b]{2}{*}{120} & 0.13 & $\begin{array}{c}796 \\
(800)\end{array}$ & $\begin{array}{c}196 \\
(217)\end{array}$ & $\begin{array}{c}243 \\
(217)\end{array}$ \\
\hline & & & 0.09 & $\begin{array}{c}953 \\
(956)\end{array}$ & $\begin{array}{c}112 \\
(118)\end{array}$ & $\begin{array}{c}64 \\
(57)\end{array}$ \\
\hline \multirow{3}{*}{$\begin{array}{l}\text { AJC146 } \\
\text { in HDFD }\end{array}$} & \multirow{3}{*}{90} & \multirow{3}{*}{230} & 0.25 & $\begin{array}{r}696 \\
(696) \\
\end{array}$ & $\begin{array}{c}140 \\
(1+1)\end{array}$ & $\begin{array}{c}275 \\
(202) \\
\end{array}$ \\
\hline & & & 0.18 & $\begin{array}{c}836 \\
(837)\end{array}$ & $\begin{array}{c}144 \\
(153)\end{array}$ & $\begin{array}{c}213 \\
(188)\end{array}$ \\
\hline & & & 0.22 & $\begin{array}{c}968 \\
(972)\end{array}$ & $\begin{array}{c}96 \\
(98)\end{array}$ & $\begin{array}{c}72 \\
(57)\end{array}$ \\
\hline
\end{tabular}

${ }^{a} \mathrm{E}-\mathrm{O}$ coefficient measured by simple reflection at the wavelength of 1.31 $\mu m:{ }^{6}$ The order parameter $\Phi=1-\left(A_{A} A_{n}\right)$. where $A_{0}$ and $A$ are the absorbance maxima for the unpoled and poled samples at normal incidence: 'Gaussian de-convoluted absorption maxima of thin films by UV $\mathrm{sis}$ spectroscopv before and after poling: "The full width at half-mas of a Gaussian sub-peak in the absorption spectra before and after poling: ${ }^{\text {e}}$ The integrated area of a Gaussian sub-peak from the absorption spectra before and after poling.

film of AJC1+6 in PMMA showed with $120 \mathrm{pm} / \mathrm{V}$ of $\mathrm{r}_{33}$ has two order parameters. 0.13 for the main peak and 0.09 for the shoulder peak. Further studies on the origin of the shoulder and its behavior are in progress. We have also performed a similar de-convolution of the spectra for binary glass of doped AJC146 in HDFD. The ordering for the composite HDFD with doped $\mathbf{A J C 1} 46$ was dependent on poling field strength as shown in Figure 6. Strong absorption bands covered from 600 $\mathrm{nm}$ to $1100 \mathrm{~nm}$ can be exactly de-convoluted into three distinct absorption peaks, i.e. peak $\mathrm{B}$. A1, and $\mathrm{A} 2$. The first peak. B. located in the high energy side of the spectrum is assigned as the charge transfer peak of self-assembled chromophore HDFD while $\mathrm{Al}$ and A2 peaks are from doped AJC146.

We have not seen any increased broadening effect of absorption in this binary system respectively from their relatively consistent fractions of each spectrum. Both peak B and $A 2$ even show band narrowing, and their full width at half-nax (FWHM or $\Gamma_{5}$ ) are $24 \mathrm{~lm}$ and $12 \mathrm{~nm}$ which is smaller than those of AJC146 in PMMA. respectively. Relevant parameter values of these de-convolutions can be compared in Table 1 . It is noted that ligher order parameters. $\Phi=0.25$ for HDFD and 0.18 (A1 area). 0.22 (A2 area) for AJC146 have also shown enhanced E-O activities up to 230 $\mathrm{pm} / \mathrm{V}$. The large E-O activities and enhanced order parameter of the binary composites suggest several critical structural facts about the approach: the self-assembly of HDFD based on the $\mathrm{Ar}-\mathrm{Ar}^{\mathrm{F}}$ interactions is robust enough not to be disturbed by the addition of guest chromophore: the dielectric properties were mainly dictated by the host self-assembly so that the poling field as high as $90 \mathrm{~V} / \mu \mathrm{m}$ could be applied to the composites: the poling efficiency of AJC1+6 in self-assembled HDFD are significantly improved by the cooperative effect.

\section{Conclusion}

In summary we have demonstrated that the electrode contact poling is very efficient and induces a stable polar ordering in the films of self-assembled E-O glassy chromophores. Self-assembled NLO chromophores have been utilized for quantitative determination of the chromophore order induced under contact poling by spectroscopic changes. The enhanced order parameter in the binary composite has contributed to high E-O activities in self-assembled NLO materials. These results suggest that self-assembled cluromophore matrix can help organize a doped chromophore and improve the polar order cooperatively.

Acknowledgments. This work was supported by University Research Program in Hannam University (2008). Tae-Dong Kim acknowledges the Korea Research Foundation Grant supports funded by the Korean Govenment (MOEHRD, Basic Research Promotion Fund) (KRF-2008-331-D00157).

\section{References}

1. (a) Zheng. X.: Sinyukov, A.; Hayden, L. M. Appl Phys. Letr. 2005, 87,081115. (b) Xu, Q.; Schmidt, B.: Pradhan, S.; Lipson, M. Nature 2005, 435, 325. (c) Jang, H.-N.; Lee, G.-Y.; Lee, J.-Y. Bull. Korean Chemt. Soc 2008, 29,811. (d) Cho, M. J.; Kim. T. Y.: Kim. T. H.: Lee, S. H.: Dalton, L. R.: Choi, D. H. Bull. Korean Chem. Soc. 2005, 26, 77.

2. (a) Kuo, Y.-H.: Luo, I.: Steier, W. H.: Jen, A. K.-Y. IEEE Photon. Tech. Lett. 2006, 18, 175 . (b) Kim, S.-K.; Hung, Y.-C.; Seo, B.-J.; Geary, K.: Yuan, W.; Bortnik, B.; Hetteman, H. R.; Wann, C.; Steier, W. H.; Zhang, C. Appl. Pliss. Lett. 2005, 87,061112.

3. (a) Enami. Y: Derose. C. T:: Mathine D.: Lovchik. C.: Greenlee, C.; Norwood, R. A.; Kim, T.-D.; Luo, J.; Tian, Y.; Jen, A. K.-Y; Pevghambarian, N. Nature Photon, 2007, 1,423 . (b) Chen, H.; Chen, B.: Huang, D.: Tin, D.: Luo, T.; Ten, A. K.-Y.; Dinu, R. Appl Phys. Lett. 2008, 93, 0435071 
4. Baehr-Tones, T.; Penkov, B.; Huang, J.: Sullivan, P.; Davies, T.; Takayesu, I.; Luo, J.: Kinn, T.-D.: Dalton, L., Ten, A.: Hochberg, M: Scherer, A. Appl Phys. Lett. 2008, 92, 1633031.

5. (a) Rau, I.; Armatys, P.; Chollet, P.-A.; Kajzar, F.; Bretonnierer, Y.; Andraud, C. Chent. Phns. Lett. 2007, 42, 329. (b) Enami, Y.; Meredith, G.: Peyghambarian, N.: Kawazn, M.; Ten, A. K.-Y. Appl Phys Lett 2003, 82,490. (c) Kajzar, F.: Lee, K.-S.; Ten, A. K.-Y. Adi: Potym. Sci. 2003, 16I, 1 .

6. Singer, K. D.: Kuzvk, M. G.; Holland, W. R.: Sohn, I. E.; Lalanna, S. J.: Comizzoli, R. B.; Katz, H. E.: Schilling, M. L. App. Phs. Lett 1988, $53,1800$.

7. Inaba, R.; Sagawa, M.; Isogai, M.; Kakuta, A. Mfacromolecriles 1996, 29, 2954

8. Kim, T.-D; Kang, J-W: Luo, J.: Tang, S.-H.: Ka, J-W.: Tucker, N.; Benedict, J. B:; Dalton, L. R.: Gray, T.; Oveney, R. M:; Park, D. H.; Hennan, W. N.; Ten, A. K.-Y. J. Am. Chem. Soc. 2007, $129,488$.

9. Teng, C. C.; Man, H. T. Appl. Phus. Lett. 1990, 56, 1734

10. (a) Paloczi, G. T.; Huang, Y.: Yariv, A.: Luo, J.: Jen, A. K.-Y.
Appl. Phss Lett. 2004, 85, 1662-1664. (b) Sinvukov, A. M.; Leahy, M. R.: Hayden, L. M.: Haller, M.: Luo, J.; Ten, A. K-Y:; Dalton, L. R. Appl. Plns. Lett. 2004, 85, 5827-5829.

11. Kim, T.-D.; Luo, J.; Ka, T.-W.; Hau, S.; Tian, Y; Shi, Z.; Tucker, N. M.; Jang, S.-H.; Kang, J.-W; Jen, A. K.-Y. Adh. Mloter: 2006, 18, 3038 .

12. (a) Kilbinger, A. F. M.; Grubbs, R. H. Angew. Chem. Int. Ed. 2002, 11, 1563. (b) Watt, S. W; Dai, C; Scott, A. J.; Burke, J. M.; Thomas, R. L.; Collings, J. C.; Viney, C.; Clegg. W; Marder, T. B. Angew: Chem. Int. Ed. Engl. 2004, 43, 3061

13. Ryu, T.-H.; Cho, B.-K.; Lee, M. Bull. Korean Chent Sac. 2006, 27,1270 .

14. Mortazavi, M. A.; Knoesen, A.; Kowel, S. T; Higgins, B. G:; Dienes, A. J. Opt. Soc. Ant. B 1989,6,733.

15. Ray, P. C.; Das, P. K. Eur: Polmm. J. 1996, 32, 51 .

16. (a) Biswas, N.; Umapathy, S. J. Ramon Spectrosc: 2001, 32,471. (b) Rodriguez, V:; Adamietz, F.: Sanguinet, L.; Buffeteau, T:; Sourisseau, C. J. Phys. Chent. B 2003, 107, 9736. 